\title{
Código de Ética de la Sociedad de Biología de Chile*
}

TÍTULO I

Sobre principios generales de la experimentación biológica

Art. 1: La Sociedad de Biología de Chile declara su respeto y valoración positiva a toda forma de vida y se involucra en la preservación y mejora de las condiciones de vida en la Tierra.

Art. 2: La Sociedad de Biología de Chile declara su vocación de estudiar, conocer, comprender, explicar, entender científicamente los procesos bióticos.

Art. 3: La Sociedad de Biología de Chile publicará y actualizará cada cuatro años los Códigos de Ética, a los que adhiere, referentes a la experimentación en seres vivos, basados en los principios declarados en los artículos anteriores y que han sido aprobados por las organizaciones internacionales de la humanidad.

Art. 4: La Sociedad de Biología de Chile considera que todo conocimiento, dato, técnica, creados u obtenidos por miembros son patrimonio de la humanidad, con el debido reconocimiento de autoría, validación y comunicación. La comercialización, patentación y derechos de propiedad de los aportes de los socios se regirán por la Ética y Legislación generales de Chile al respecto.

\section{TÍTULO II}

De la Ética de los socios, las profesiones e instituciones

Art. 5: En caso que un socio sea un profesional regirán para él, además de este Código, tanto las normativas éticas generales de su profesión como las del Colegio Profesional respectivo. Si el socio no posee título profesional y trabaja en un campo profesional valdrán para él esas mismas normativas éticas.
En el caso que no haya normativas en Chile para esa profesión o, que habiendo Colegio no tenga normativas, valdrán las internacionales aprobadas por el Colegio respectivo. Si no hay en absoluto normativas valdrán las que se enuncian en este Código.

Art. 6: Todo socio que trabaja en una institución que posee códigos de ética deberá ajustarse a ellos y al presente Código.

\section{TÍTULO III}

Fraude o faltas en experiencias científicas

Art. 7: Se considera fraude en la realización de una experiencia científica:

a) La inclusión de elementos que no pertenecen a ella o la exclusión de elementos que le pertenecen, realizados deliberadamente, de modo tal, que un revisor de la experiencia que se presenta, o lector de su descripción, se forme una idea, valorización o juicio distintos de los que se formaría si tuviera la visión de experiencia directa o su descripción estricta. Un caso extremo es la invención completa de la experiencia.

b) La alteración deliberada de algún elemento de la experiencia que cambia la idea, juicio o valoración, que revisor o lector pudiese tener si no hubiese ocurrido la alteración.

Art. 8: Se considera falta a la ética en la experimentación científica el no atenerse a las normativas enunciadas en el Título I de este Código.

TÍTULO IV

Faltas en el trabajo colaborativo

Art. 9: Son faltas a la ética del trabajo colaborativo entre científicos: 
a) La adulteración, destrucción o apropiación de elementos de la experiencia científica que pertenecen a ese grupo de trabajo y que son necesarias para realizar la investigación o formar a los investigadores jóvenes.

b) Impedir el acceso a información necesaria para la mejor interpretación y entendimiento de la experiencia científica efectuada por el grupo.

c) Difundir, deliberadamente, oralmente o por escrito información falsa al resto del grupo, cambiando así el conocimiento o interpretación de la experiencia científica.

d) Difundir información sobre la experiencia científica fuera del grupo de trabajo sin la autorización del grupo para hacerlo.

TÍTULO V

Faltas con científicos en formación

Art. 10: Son faltas a la ética en la formación de científicos:

a) Negligencia en la entrega de elementos necesarios para su formación.

b) Imposición de normas y sistemas de trabajo que atenten contra la salud de ellos.

c) Utilización de presiones académicas para conseguir fines sentimentales, pecuniarios o de otra índole diferente a la académica.

\section{TÍTULO VI}

Relación entre colegas científicos

Art. 11: Son faltas en las relaciones entre colegas científicos:

a) Hurtar información y manejarla como si fuera propia.

b) Negar injustificadamente información o dar a otros deliberadamente información errónea.

c) Evaluar deliberadamente en forma injusta proyectos de investigación, manuscritos de artículos científicos, otros documentos o antecedentes personales necesarios para la producción, formación o contratación de científicos. d) Retardar, más allá del plazo convenido o públicamente aceptado, los informes periciales necesarios para producción científica.

e) No reconocer su incompetencia en el tema al que se le solicita su pericia para evaluar un trabajo de un colega.

f) Calumniar o descalificar a un colega en su actividad científica.

\section{TÍTULO VII \\ Participación en comités o jurados}

Art. 12: Al participar un científico en un comité editorial o jurado destinado a llenar una plaza vacante, otorgar beca, premio o distinción deberá:

a) Atenerse estrictamente a los términos de las reglas previamente acordadas sean estas públicas o privadas.

b) Abstenerse de participar si tiene compromisos previos con algunos de los candidatos o con otro jurado relacionados con el resultado del fallo.

c) Tratar a todos los concursantes o candidatos con equidad.

d) Al decidir el nombramiento de un miembro del jurado, procurar elegir a una persona reconocida públicamente como experta en la materia, imparcial y honesta.

Art. 13: Es falta, alterar cualquier parte del artículo que se presenta para su revisión en lo sustantivo sin el consentimiento de los autores. Asimismo, es falta alterar antecedentes, quitar o poner antecedentes sin consentimiento del candidato o concursante, necesarios para el fallo sobre su idoneidad.

TÍTULO VIII

Faltas éticas en publicaciones científicas

Art. 14: Son faltas éticas en la redacción y publicación de artículos científicos:

a) Aparecer en una publicación como autor sin entenderla, sin poder explicarla o sin haber participado directamente en su desarrollo. 
b) Desconocer o no citar experiencias anteriores pertinentes y relevantes.

c) Agregar elementos inexistentes o quitar elementos que deben incluirse por estar comprendidos en el diseño de la experiencia.

d) No reconocer o agradecer a las personas o instituciones que posibilitaron la realización de la experiencia.

TÍTULO IX

De la responsabilidad científica y de las sanciones

Art. 15: Los miembros de la Sociedad de Biología de Chile se obligan a cumplir responsablemente las normas del presente Código y aceptar las sanciones en el caso de cometer infracciones.

Art. 16: El directorio de la Sociedad de Biología de Chile determinará la modalidad del proceso al infractor del Código y sus sanciones.

Socios Dres:

Carlos Valenzuela Y.

Ricardo Cruz-Coke M.

Tito Ureta A.

Ricardo Bull S.

Manuel Santos A.

Miembros de la Comisión de Ética y Bioética de la Sociedad de Biología de Chile.

Nota: Este Código fue originalmente publicado en: Valenzuela C., Cruz-Coke R., Ureta T., Bull R. Código de Ética de la Sociedad de Biología de Chile Rev Méd Chile 1997; 125:71-73

Fue aprobado en la Asamblea Anual de Socios de la Sociedad de Biología de Chile, celebrada el 25 de noviembre de 2006, en la ciudad de Pucón, Chile. 
